\title{
The application of network teaching in applied optics teaching
}

Huifu Zhao, Mingxu Piao, Lin Li, Dongmei Liu

Huifu Zhao, Mingxu Piao, Lin Li, Dongmei Liu, "The application of network teaching in applied optics teaching," Proc. SPIE 10452, 14th Conference on Education and Training in Optics and Photonics: ETOP 2017, 1045246 (16 August 2017); doi: 10.1117/12.2266501

SDIE Event: 14th Conference on Education and Training in Optics and Photonics, ETOP 2017, 2017, Hangzhou, China 


\title{
The application of network teaching in applied optics teaching
}

( School of Opto-Electronic Engineering, Changchun University of Science and Technology,

Changchun , Jilin, china 130022)

\section{Huifu Zhao Mingxu Piao Lin Li Dongmei Liu}

\begin{abstract}
Network technology has become a creative tool of changing human productivity, the rapid development of it has brought profound changes to our learning, working and life. Network technology has many advantages such as rich contents, various forms, convenient retrieval, timely communication and efficient combination of resources. Network information resources have become the new education resources, get more and more application in the education, has now become the teaching and learning tools. Network teaching enriches the teaching contents, changes teaching process from the traditional knowledge explanation into the new teaching process by establishing situation, independence and cooperation in the network technology platform. The teacher's role has shifted from teaching in classroom to how to guide students to learn better. Network environment only provides a good platform for the teaching, we can get a better teaching effect only by constantly improve the teaching content.

Changchun university of science and technology introduced a BB teaching platform, on the platform, the whole optical classroom teaching and the classroom teaching can be improved. Teachers make assignments online, students learn independently offline or the group learned cooperatively, this expands the time and space of teaching. Teachers use hypertext form related knowledge of applied optics, rich cases and learning resources, set up the network interactive platform, homework submission system, message board, etc. The teaching platform simulated the learning interest of students and strengthens the interaction in the teaching.
\end{abstract}

Keywords: Network teaching; Applied optics; Teaching interaction

\footnotetext{
14th Conference on Education and Training in Optics and Photonics: ETOP 2017, edited by Xu Liu, Xi-Cheng Zhang, Proc. of SPIE Vol. 10452, 1045246 - (C) 2017 ICO, IEEE, OSA, SPIE CCC code: $0277-786 X / 17 / \$ 18 \cdot$ doi: $10.1117 / 12.2266501$
} 


\section{Introduction :}

Applied optics is an important professional basic course of optoelectronic information engineering. It is a very strong theoretical discipline, and it also emphasises on the practical application. It is vital to train the talents of Optoelectronic Information Engineering. With the deepening of teaching reform, a variety of teaching methods are applied to the teaching of applied optics. With the rapid development of network technology, the Internet and education ,as the two main driving forces to promote future social development, will affect our competitiveness in the future in terms of breadth and depth. Network education has become an important development direction of educational informationization, and stimulates the change of students' learning style. "Educational informationization, digital campus" has become the goal of the development of modern education, network teaching is scrambling to become the main subject of the teaching reform for teachers.

\section{Online teaching}

(1) Definition: the so-called network teaching is online learning or network learning, which is to establish an Internet platform in the field of education. It is a new way of learning that students learn through the PC Internet, through the network.

( 2 ) Effect: teachers should fully reflect the teaching ideas that teachers lead and students make the majority in the network teaching activities. It must not only focus on teachers' teaching, but also focus on the two aspects of the effective combination of students' study and teachers' teaching, so it could optimize the entire classroom teaching and improve classroom teaching results.

(3) The advantages of network teaching and other traditional teaching:

Large capacity:

Content is all inclusive, in the form of expression, text, graphics, animation, audio, video and other multimedia focus on the integration, using interactive visualization window to expand the amount of information, creating an information environment.

These are common features of electronic information, in which it could have a lot of teachers 
preparing materials, teaching activities news and so on.In addition, "teaching materials", "class work" and other information provide a wide range of reference materials for teachers about work and study.

Simple and convenient:

The network shows the advantages of getting information whenever and wherever it is compared to the larger information receiving methods such as reading the newspaper or books which are limited by time and space .Coupled with a clear classification of the site, coupled with a powerful search function, its simplicity is self-evident than a local search for paper information .In addition, it doesn't have any time and space constraints.

Targeted strongly:

As for teachers, something can be found on the Internet for the class, teaching content, like a virtual classroom, which plays a great complementary role for the "reality" teaching. Its targeted nature is much stronger, and the effect to the teaching of teachers and the learning of students is naturally bigger.

\section{The application of network teaching in optics teaching}

Changchun University of Science and Technology launched the BB teaching platform, in which teachers can optimize the application of optical classroom teaching and improve classroom teaching effect. Teachers assign some tasks online, and students learn independently underline or learn by group collaborative learning. By this way,it expands the teaching time and space. Teachers use hypertext to form the applied optical knowledge content, rich cases and learning resources, building a network interactive platform, work submission system, message board and so on. Through the teaching platform, teachers mobilize the initiative of students to learn better, and it strengthens the interaction in teaching very well.

(1) Task - driven teaching method

In traditional teaching, due to the limit of time and space, it is difficult for teachers to give each student free discussion time, and teaching rhythm is very difficult to adapt to different students 
whose foundations are different. This will result in those students whose foundations are weak cannot follow or students whose foundations are well may waste time. However, network teaching powerful interactive function can just solve this problem. Teachers in the BB teaching system can design the contents of different chapters into different modules. Students can freely allocate their own time. For their understanding content, they will take less time, and for their little understanding content, they will spend more time. In order to follow up students' enthusiasm of learning, there can be a variety of theme tasks to drive teaching, so that students in the process of completing the task could learn to consolidate knowledge and skills, cultivate innovative spirit and active learning habits.

The suitability and the interaction of the network environment make it more convenient for teachers and students to implement teaching tasks and complete the teaching tasks. When students encounter difficulties in the learning process, they can be helped by other students or teachers through the BBS function. Students can also discuss and solve the problems together. Implementation of the task of teaching, should pay attention to the following questions:

a) Focusing on practical tasks, tasking design should conform to the characteristics of students, considering the reality of students. Teachers should try their best to combine content of students' learning and life or other subjects to increase students' interest in learning and cultivate students' abilities to solve practical problems.

b) Tasks clear objectives and requirements, the task should be operational, appropriate size, consider the abilities to complete the task from teams or each person.

c) It is coherent between tasks and tasks of the interrelated tasks. We should make it to form a task chain, to strengthen the mutual penetration between tasks, so that students can achieve mastery through a comprehensive study of the subject and grasp the whole category by grasping a typical example, training students to analyze problems and deal with comprehensive problems.

(2) Return to life teaching method

Return to life learning is learning activities that the students research under the guidance of teachers, from the natural, social and life selection and application of optical related content, and in 
the research process the students take the initiative to acquire knowledge, apply knowledge, and solve problems. Through the return to life learning it can promote their positive attitude towards learning and good learning strategies, and cultivate students' innovative spirit and practical ability. There is a discovery column about optical life designed in the BB system. Students upload content related to the column through their data collection and collation, but this content cannot be the same as other students'. This content will be made for students' grades, and it will be recorded by teachers. With the accumulation of time, the column will become the most interesting module in BB system. It greatly inspires the enthusiasm of students to learn.

(3) Cooperative teaching method

With the design of learning objectives, the establishment of learning groups, the use of BB network environment open, interactive, team members can learn from each other and help each other, achieving resource sharing, complementary advantages in the BB system.

(4) Online job management

Teachers publish the task in the BB system, and students submit the task in the BB system. Teachers can make full use of online functions to achieve communication between teachers and students, students and students, to get timely and rapid feedback, to greatly reduce the blindness of teaching, to improve classroom teaching efficiency. The same time, it achieves two-way interaction, and not only it could increase student participation, but make students in a dominant position in learning activities.

\section{The change of network teaching for optical teaching}

(1) Changes in teaching content. The network teaching provides learners with the necessary information environment, and provides various teaching content. In addition, it greatly enriches and expands the knowledge of books so that students can learn more in less time.

(2) Changes in the teaching process and the role of teachers. In the teaching of the network, teachers are no longer the embodiment of knowledge, the teacher's role changes, in which they become a student to guide students to understand "where" and "how" to get their own knowledge, to 
master the knowledge tools and methods of handling information according to the needs of knowledge. In the network teaching, the teaching process is changed from traditional knowledge explanation or classroom narration to new teaching process such as creating situation, cooperative learning, autonomous learning, discussion and learning in the network environment.

(3) Changes in the way that students learn. In the network teaching, students must have a high degree of autonomy learning ability, and they must learn to use all kinds of resources to actively build knowledge. Students should not only master the learning of knowledge, but also learn to collaborate to learn, to communicate with others, to share information. They require students in the learning process to be always in the dominant position, to be with a high degree of autonomy.

\section{References:}

[1] Liu Yandong's speech on the work conference of comprehensive improvement of Higher Education Quality.

[2] The declared relevant documents of 2012 years "national boutique resource sharing course". 